\title{
Analysis of College Research Paper Output Based on InCites Database - Take the Northwestern Polytechnical University for Example
}

\author{
Fan Zong ${ }^{1} \&$ Lifang Wang ${ }^{1}$ \\ ${ }^{1}$ Northwestern Polytechnical University, Xi'an, China \\ Correspondence: Fan Zong, Northwestern Polytechnical University, Xi'an, China E-mail: zongfan@nwpu.edu.cn
}

Received: October 15, 2016 Accepted: November 21, 2016 Online Published: November 30, 2016

doi:10.5539/jpl.v9n10p133 URL: http://dx.doi.org/10.5539/jpl.v9n10p133

\begin{abstract}
This paper uses scientific metrology methods to analyse the current status and the development trend of the research paper output of NWPU (Northwestern Polytechnical University) based on the Incites database from 1981 to 2014. The result shows that the research publications have increased notablely. Whereas, there still has some problems need to be solved, such as low quality and non-widely distributed subject areas. This paper hereby proposes some advice that NWPU should, starting with perfecting the research evaluation mechanism, improve the internationalization level and international influence while encourage the coordinated development of new-rising subjects and interdisciplines.
\end{abstract}

Keywords: research paper, incites database, ESI subjects

\section{Introduction}

Research paper is an important aspect of scientific research output, which suggests the intrinsic quality and level of the scientific research. So it's one of the most commonly used measures in the scientific evaluation research and practical activities to evaluate a nation's scientific research level. The National Program for Medium- and Long-Term Educational Reform and Development document ( 2010-2020 ) issued in 2010 suggested explicitly that our nation should reach the goal by 2020 as follows: First, build some internationally famous, characteristic and high-level colleges. Second, several colleges reach or approach to the level of world class universities. Third, international competitiveness of higher education will significantly strengthened. This paper, taking the statistical data of Incites database as the object of study, uses the scientific metrology method to study the current status and the development trend of the research paper output of NWPU and examine thoroughly the existing insufficient and development status of the scientific research, meanwhile confirm the current position in the international scientific research institutions so as to provide an accurate direction and approach for further development into a world class high level university.

\section{Incites Database}

Incites database is an analysis and evaluation tool for measuring the scientific research level and tracking the scientific development trend built by the global largest information agent Thomson Reuters on the basis of collecting and analyzing the top-three citation databases of Web of Science (SCI/SSCI/AHCI), It synthesizes all kinds of literature measuring indexes and annual international benchmark data of all subjects during the recent 30 years (1981-now) and is updated yearly. Incite database mainly includes three parts: RPP (Research Performance Profiles), GC (Global Comparisons) and IP (Institutional Profiles). RPP are customization data, which could acquire the information about organizations, individuals and themes according to the user needs and adopt multiple indexes to make deep analysis. GC are initialized data, which include data information of Web of Science from more than 2000 institutions around the world. Users can compare the overall situation and scientific influence of each institution by selecting the threshold and the subject. This paper uses the data from the Incites database from 1981 until 2014.

\section{Total Output of Scientific Research Papers}

\subsection{Web of Science Documents}

NWPU has published 11783 research papers on Web of Science during 1981 and 2014. We can obviously see 
that the increase of research papers of NWPU presented good development trend, the number of published papers increased year by year, especially after 2007 there appeared a substantial increase.

\subsection{Times Cited and Cites per Document}

The total times cited and average cites per document of NWPU are shown in figure 1. The data was selected every five years. We can see that both of them remain increase rapidly, which not only show great improvement of the quality of scientific research of NWPU, but also reflect that the researcher had paid much more attention to publishing papers. Especially since 2008, the paper requirement for professional and technical staff promotion had heightened year by year, largely arousing the enthusiasm of teachers publishing high-level papers.

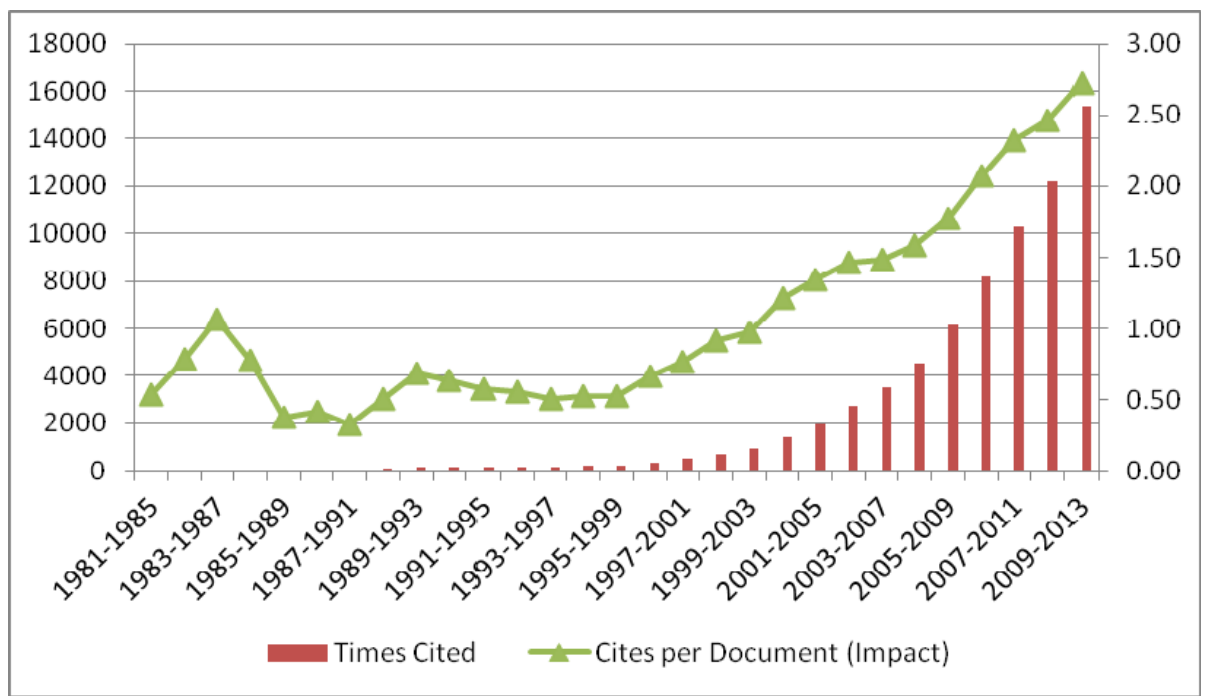

Figure 1. Times Cited and Cites per Document (every five years)

We can also notice from figure 2 that, compared with the total number of papers and total times cited, this university has a low average cites per document, less than 3 till 2014. The average cites per document suggests the average level of research influence of a single paper. It's an important measure to evaluate the academic level of the research paper. So this illustrates that, with the rapid increase of the quantity of papers, the university should also pay attention to the quality of the papers.

\section{Authors, Journals and Top Research Fields}

\subsection{Top Producing Authors and Most Cited Authors}

During 1981 to 2014, the authors who have published the most papers on Web of Science in NWPU are in sequence HeJun Li, LiTong Zhang, LaiFei Cheng, HengZhi Fu and KeZhi Li, et al. The most cited authors are HeJun Li, XiaoPeng Zhao, LiTong Zhang, LaiFei Cheng and KeZhi Li, et al, among the top ten authors there are eight authors work on material science. So we can see that the material science is the preponderant discipline of NWPU. However, from another perspective it suggests that the subject distribution is excessively concentrated, the preponderant disciplines are relatively less in our university. The detailed information about the top-ten producing authors and the top-ten most cited authors are shown in figure 2 and figure 3 , respectively. 


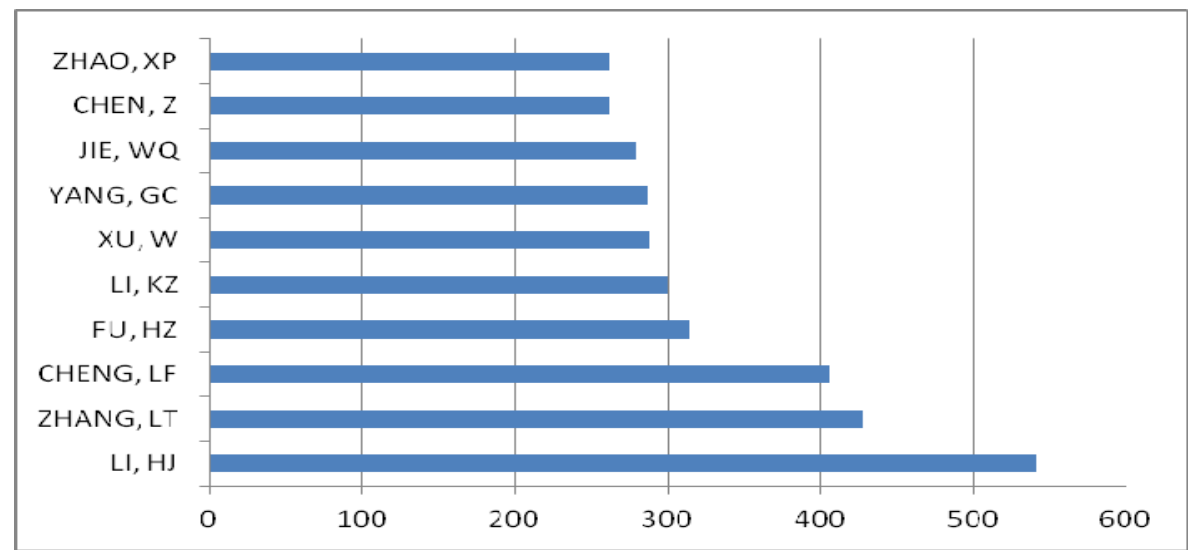

Figure 2. The top-10 producing authors

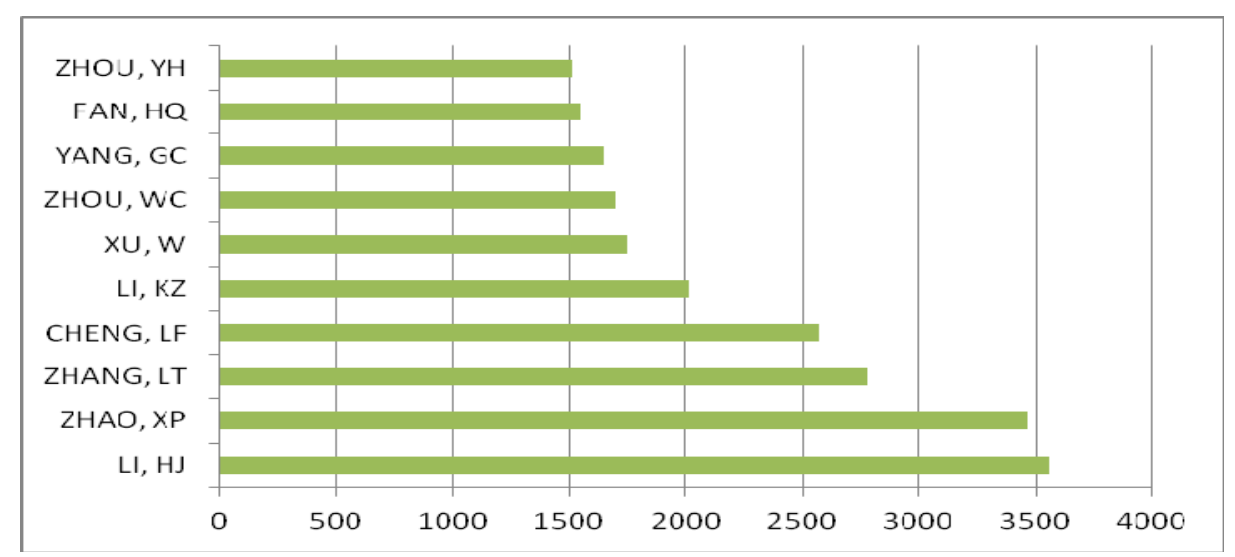

Figure 3. The top-10 most cited authors

\subsection{Highly-included Journals}

NWPU has published in more than 1413 different journals on Web of Science during 1981 to 2014, but more than 1200 of them include less than 10 papers each and only 42 kinds of journals include more than 50 papers each. The top- 5 journals on which most papers are published are shown in table 1 . It is clear that the journal with the most publications does not have the highest times cited, even in the rank of six, meaning that the journal is not the most influential.

Table 1. The top-5 journals

\begin{tabular}{clccc}
\hline \multicolumn{1}{c}{ Num. } & \multicolumn{1}{c}{ Journal } & $\begin{array}{c}\text { Total } \\
\text { papers }\end{array}$ & $\begin{array}{c}\text { Total } \\
\text { citation }\end{array}$ \\
\hline 1 & $\begin{array}{l}\text { RARE METAL MATERIALS AND ENGINEERING } \\
2\end{array}$ & $\begin{array}{l}\text { MATERIALS SCIENCE AND ENGINEERING } \\
\text { A-STRUCTURAL MATERIALS PRO }\end{array}$ & 367 & 2,045 \\
3 & $\begin{array}{l}\text { ACTA PHYSICA SINICA } \\
4\end{array}$ & $\begin{array}{l}\text { TRANSACTIONS OF NONFERROUS METALS } \\
\text { SOCIETY OF CHINA }\end{array}$ & 257 & 1,438 \\
5 & JOURNAL OF ALLOYS AND COMPOUNDS & 223 & 548 \\
\hline
\end{tabular}

\subsection{Most Active Subject Areas}

The most active subject areas are worth our attention, through which we can find the overall research hotspot of 
NWPU and the overall worldwide inclusion situation. It is important to study the subject development tendency for our university. The top-5 active subject areas are shown in table 2, from which we can see that the most active subject areas of our university are material science, physics, chemistry, mechanics and engineering. We could also notice that the active subject areas are too concentrated, while newly developing and crossing fields are too few.

Table 2. The top-5 active subject areas

\begin{tabular}{clc}
\hline Num. & \multicolumn{1}{c}{ Active subject areas } & Total publications \\
\hline 1 & MATERIALS SCIENCE, MULTIDISCIPLINARY & 4072 \\
2 & METALLURGY \& METALLURGICAL ENGINEERING & 2538 \\
3 & PHYSICS, APPLIED & 1108 \\
4 & CHEMISTRY, PHYSICAL & 811 \\
5 & PHYSICS, MULTIDISCIPLINARY & 792 \\
\hline
\end{tabular}

\section{Article Type and Funds}

\subsection{Article Type}

The type of research paper on Web of Science written by NWPU is mainly ARTICLE in the recent 30 years. The total ARTICLE publication number is 11517 , which takes up $97.7 \%$ of the total publications.

\subsection{Funds}

The funds resources of NWPU publishing research paper on Web of Science during the recent 30 years are relatively widespread, up to 2000 different types. among which NSFC ( Natural Science Foundation of China) is the main resource $(4060,34 \%)$ due to the size of the funded publication. The others funds are the special funds of the central university fundamental scientific research operating expenses, the national key fundamental research development plan (973), New Century Talent Supporting Project by education ministry, National High Technology Research and Development Program of China (863), NWPU School Funds, The ministry of education by the specialized research fund for the doctoral program of higher education, etc. These funds have provide finance for publication for more than $50 \%$ papers.

\section{Collaborating}

The organizations collaborated with NWPU to publish papers on the Web of Science during the recent 30 years are more than 1173. Ranked by the number of cooperated papers, the top- 2 cooperative institutes are Xi'an Jiaotong University (329) and the Chinese Academy of Sciences (302). The top-3 cooperative institutes abroad are the Hong Kong Polytechnic University (135), national academy of sciences of France (71) and University of California (53), respectively. Fifteen institutes have cooperative publications more than 50, taking up $1.2 \%$ of all the cooperative institutes. And the number of cooperative papers by the 15 research institutions takes up $23.8 \%$ of all the cooperative publications.

Among the top-fifteen collaborating institutes, there are 5 universities in Shaanxi province (Xi'an Jiaotong University, Northwest University, Xi'an University, The Fourth Military Medical University and Shaanxi Normal University). One of the fifteen institutes is Northwest Institute for Nonferrous Metal Research(NIN). Clearly, these closely connected collaborating institutes are strongly local regional.

These collaborated nations and the international cooperation papers are sum up to 48 and 1940, respectively. There are 8 nations having more than 50 international cooperative papers, which are USA (569), France (221), the the United Kingdom (199), Germany (186), Canada (119), Japan (119), Australia (107) and Singapore (64), taking up $16.7 \%$ of all the cooperative nations and the number of cooperative papers taking up $81.6 \%$ of all the collaborating papers.

\section{Conclusion and Suggestion}

Overall, NWPU has a good development tendency which is reflected in the maintaining steadily increase of the quantity, quality and influence of the research paper output year by year. However, except for the total amount of the research paper, the superiorities of other indexes are not obvious. The subjects are developed imbalanced and the influence on frontier interdisciplines is little. To develop NWPU into a world class university, leap development is necessary. So we suggest paying attention to the following aspects: 
First, further improve the scientific research evaluation mechanism and focus on the innovation and quality of scientific research papers. Build research influence and innovation oriented scientific research evaluation system and methods referring to the internationalized evaluation standard. Make policy to stress on the fundamental research and theoretical research. Abandon the general traditional researches and encourage teaching staffs to achieve high-level research fruits.

Second, improve the internationalization level and the international influence. Although the number and quality of publications have increased, NWPU is still far away from the world class universities in internationalization level and international influence. Therefore, we should reinforce the international communications and expand international cooperation projects to increase publications and link ourselves with world-class universities and subjects, so as to improve the subject international influence of NWPU.

Third, pay close attention to international research frontiers and encourage to develop new-rising subjects and cross subjects. With the rapid development of the global economy and the fast rise of the tertiary industry, we need to strengthen the cutting-edge research and intersecting research. Besides, we should find new growth points of subjects to promote the discipline integration, optimize the discipline structure, integrate discipline resources and promote synergetic development of new-rising subjects based on the integration of multiple subjects while maintaining the advantage disciplines.

\section{Acknowledgements}

The research work was supported by NWPU's higher education research fund No. 2015GJZ09.

\section{References}

He, D. F. (2011). International comparative study on output conditions of China's high-impact papers. China Soft Science, (9).

Qiu, J. P. et al. (2007). Metrological Analysis on Science Research Competitive Abilities of Chinese Universities Based on ESI Database. Library and Information Service, (5).

Wang, Y. X. et al. (2006). Statistical Indicators' Principle and Data Process of ESI. Library and Information Service, (9).

Ye, W. P. et al. (2013). How far is it from China's scientific research strength compared to the United States research based on the InCites database. China Higher Education Research, (10).

\section{Copyrights}

Copyright for this article is retained by the author(s), with first publication rights granted to the journal.

This is an open-access article distributed under the terms and conditions of the Creative Commons Attribution license (http://creativecommons.org/licenses/by/4.0/). 